\title{
Neuronal Correlates of Serial Decision-Making in the Supplementary Eye Field
}

\author{
(Dachary M. Abzug ${ }^{1}$ and $₫$ Marc A. Sommer ${ }^{1,2,3}$ \\ ${ }^{1}$ Department of Biomedical Engineering, Pratt School of Engineering, ${ }^{2}$ Center for Cognitive Neuroscience, and ${ }^{3}$ Department of Neurobiology, Duke School \\ of Medicine, Duke University, Durham, North Carolina 27708
}

Human behavior is influenced by serial decision-making: past decisions affect choices that set the context for selecting future options. A primate brain region that may be involved in linking decisions across time is the supplementary eye field (SEF), which, in addition to its well known visual responses and saccade-related activity, also signals the rules that govern flexible decisions and the outcomes of those decisions. Our hypotheses were that SEF neurons encode events during serial decision-making and link the sequential decisions with sustained activity. We recorded from neurons in the SEF of two rhesus monkeys (Macaca mulatta, one male, one female) that performed a serial decision-making task. The monkeys used saccades to select a rule that had to be applied later in the same trial to discriminate between visual stimuli. We found, first, that SEF neurons encoded the spatial parameters of saccades during rule selection but not during visual discrimination, suggesting a malleability to their movement-related tuning. Second, SEF activity linked the sequential decisions of rule selection and visual discrimination, but not continuously. Instead, rule-encoding activity appeared in a "just-in-time" manner before the visual discrimination. Third, SEF neurons encoded trial outcomes both prospectively, before decisions within a trial, and retrospectively, across multiple trials. The results thus identify neuronal correlates of rule selection and application in the SEF, including transient signals that link these sequential decisions. Its activity patterns suggest that the SEF participates in serial decision-making in a contextually dependent manner as part of a broader network.

Key words: decision-making; frontal cortex; macaque; metacognition; rule use; saccades

\section{Significance Statement}

Much research has gone into studying the neurobiological basis of single, isolated decisions. An important next step is to understand how the brain links multiple decisions to generate a coherent stream of thought and behavior. We studied neural activity related to serial decision-making in an area of frontal cortex known as the supplementary eye field (SEF). Neural recordings were conducted in monkeys that performed a serial decision-making task in which they selected and applied rules. We found that SEF neurons convey signals for serial decision-making, including transient encoding of one decision at the time it is needed for the next one and longer-term representations of trial outcomes, suggesting that the region plays a role in continuity of cognition and behavior.

\section{Introduction}

Serial decision-making helps to maintain continuity of behavior. The outcomes of past decisions inform current choices that, in turn, set the context for evaluating and selecting later options. For

Received Dec. 27, 2017; revised May 31, 2018; accepted July 4, 2018.

Author contributions: Z.M.A. and M.A.S. wrote the first draft of the paper; Z.M.A. and M.A.S. edited the paper; Z.M.A. and M.A.S. designed research; Z.M.A. performed research; Z.M.A. and M.A.S. analyzed data; Z.M.A. and M.A.S. wrote the paper.

This work was supported by the National Science Foundation (Grant 1539687 to M.A.S.). We thank Jessi Cruger for monkey care expertise.

The authors declare no competing financial interests.

Correspondence should be addressed to Dr. Marc A. Sommer, Department of Biomedical Engineering, Duke University, 1427 CIEMAS Building, Box 90281, 101 Science Drive, Durham, NC. E-mail: marc.sommer@duke.edu.

DOI:10.1523/JNEUROSCI.3643-17.2018

Copyright $\odot 2018$ the authors $\quad 0270-6474 / 18 / 387280-13 \$ 15.00 / 0$ example, an NFL quarterback deciding which play to call will consider both environmental factors (e.g., field position) and the history of recent calls. At midfield, if passes have yielded more yards than runs, the quarterback may be biased toward pass plays until outcomes change. How the brain makes individual decisions has been the focus of much recent work (Gold and Shadlen, 2007; Shadlen and Kiani, 2013; Lee and Seo, 2016), but the neural mechanisms that link decisions across time remain poorly understood.

One previous study examined the neural basis of serial decision-making using a task in which macaques made a perceptual decision and then bet on their performance to receive reward (Middlebrooks and Sommer, 2011, 2012). Neurons in the supplementary eye field (SEF), but not the prefrontal cortex (PFC) or frontal eye field (FEF), exhibited sustained activity after the per- 
ceptual decision that predicted the wager. Other work showed that SEF neurons are sensitive to trial outcome, reward, variables such as conflict and difficulty that affect reward likelihood, and future behavior (for review, see Abzug and Sommer, 2017). SEF activity related to trial outcome reflects whether a decision yields reward (Amador et al., 2000; Stuphorn et al., 2000; Purcell et al., 2012; Donahue et al., 2013; Kawaguchi et al., 2015). Such "performance monitoring" signals can extend into later trials (Donahue et al., 2013). SEF reward-related signals also can manifest as mixed selectivity in combination with variables such as target location, target identity, and expected reward (Uchida et al., 2007; So and Stuphorn, 2012; Donahue et al., 2013; Kawaguchi et al., 2015). SEF neurons tend to fire more when conflict is higher, such as when saccades must be inhibited to flashed targets (Schlag-Rey et al., 1997; Olson and Gettner, 2002), and SEF lesions in humans cause impairments in resolving this type of conflict (Husain et al., 2003; Parton et al., 2007). SEF neurons are modulated by task rules (White and Wise, 1999; Olson and Gettner, 2002), encode visual stimuli in a rule-contingent manner (Missal and Heinen, 2004; Kim et al., 2005), and tend to fire more for rules that are harder to apply (Schlag-Rey et al., 1997; Olson and Gettner, 2002).

Prediction or anticipation is of particular relevance to serial decision-making because the crux of the behavior is that the outcome of one decision predicts the next decision. Several lines of evidence implicate the SEF in predictive functions. When reward probabilities and sizes are provided explicitly, SEF activity anticipates the expected value of reward (So and Stuphorn, 2012). Baseline and visual responses in SEF encode future saccade direction well in advance of movement (Coe et al., 2002) and SEF activity predicts the performance of upcoming prosaccades and antisaccades (Amador et al., 2000). SEF microstimulation decreases the latency of anticipatory smooth pursuit eye movements (Missal and Heinen, 2004) and transcranial magnetic stimulation of human SEF impairs prediction of smooth pursuit target trajectories (Nyffeler et al., 2008).

The literature therefore suggests myriad ways in which the SEF may contribute to serial decision-making. Here, we studied SEF neural activity during a novel oculomotor task that required two linked decisions per trial. Monkeys decided on rules that guided later, visual decisions (Abzug and Sommer, 2018), essentially the reverse of the task used by Middlebrooks and Sommer (2012) in which visual decisions informed later, wagering decisions. We tested two hypotheses. First, based on the body of literature, we hypothesized that SEF neurons signal key events in the serial decision-making task, such as when rules are set and when trial outcomes are revealed. Second, based on the results of Middlebrooks and Sommer (2012), we hypothesized that SEF neurons exhibit sustained activity that links the two decisions of our task, selecting a rule and applying it to a visual discrimination.

\section{Materials and Methods}

\section{Neuronal recordings}

Two rhesus monkeys (Macaca mulatta; Monkey S: male, $10.0 \mathrm{~kg}$; Monkey M: female, $5.4 \mathrm{~kg}$ ) were surgically prepared for neuronal recordings and eye position measurements. Using aseptic procedures, ceramic screws and an acrylic implant were affixed to the skull. Bound into the acrylic was a recording chamber positioned over a craniotomy for accessing the SEF (stereotaxic coordinates A25, L0) and a head-restraint socket placed just posterior to the chamber (Crist Instrument). In the same surgery, a scleral search coil was implanted for recording eye position (Judge et al., 1980). Animals recovered for 1-2 weeks before behavioral training resumed. Procedures were approved by and conducted under the auspices of the Duke University Institutional Animal Care and Use Committee and complied with the guidelines set forth in the United States Public Health Service Guide for the Care and Use of Laboratory Animals.

We recorded neurons in the SEF by advancing a parylene-insulated tungsten electrode (0.3-1 M $\Omega$ impedance at $1 \mathrm{kHz}$; FHC) through a 23TW gauge guide tube using a custom microdrive system (Laboratory of Sensorimotor Research, National Institutes of Health). Guide tubes were held by a plastic grid with $1 \times 1 \mathrm{~mm}$ hole spacing (Crist Instrument) attached inside the recording chamber. The SEF was identified by moderate-current microstimulation (typically $50-100 \mu \mathrm{A}$ ) that evoked or delayed saccades (Schlag and Schlag-Rey, 1987; Russo and Bruce, 1996) or by anatomical reference based on MRI images. Standard extracellular recording techniques were used to isolate action potentials of single neurons (Sommer and Wurtz, 2004). All data were collected using the REX real-time system (Hays et al., 1984), Spike2 (CED, RRID: SCR_000903), and RHD2000 Evaluation System Software (Intan Technologies). Action potentials were sorted offline using Spike2 and analyses were performed using MATLAB (R2016a; The MathWorks, RRID: SCR_001622). Eye position was sampled at $1 \mathrm{kHz}$ and saccades were detected online using velocity and acceleration thresholds. During fixations, eye position had to be maintained in $4^{\circ} \times 4^{\circ}$ window around visual stimuli. Both raw eye position traces and saccade onset and offset timing were recorded and saved.

\section{Experimental design and statistical analysis}

Serial decision-making task. Monkeys performed a two-stage task that required sequential, linked decisions. Each trial consisted of a rule selection stage followed by a rule implementation stage (Fig. $1 A$ ). During rule selection (Fig. 1A, left), a rule was established either because the monkey actively chose it (self-selected trials) or because the monkey passively observed it (instructed trials). We demonstrated previously that the monkeys select rules purposely, not randomly, in self-selected trials (Abzug and Sommer, 2018). The monkeys were trained to associate colored stimuli with two abstract behavioral rules: the size rule, $R_{\mathrm{S}}$, which meant "pick the smaller target," and the brightness rule, $R_{\mathrm{B}}$, which meant "pick the darker target." For Monkey $\mathrm{S}$, a green stimulus represented $R_{\mathrm{S}}$ and a red stimulus represented $R_{\mathrm{B}}$; for Monkey $\mathrm{M}$, these color-rule assignments were reversed. Because the monkeys made saccades to the colored stimuli, as described in the next paragraph, they were called "rule targets." For further details of training and selection of task parameters, see our previous study (Abzug and Sommer, 2018).

To start each trial, a monkey fixated a central white spot for 400-600 ms (pseudorandomized) and then the rule targets appeared in the periphery, one in each visual hemifield (Fig. $1 A$, left). The rule targets were different in self-selected trials (one red, one green) but were the same in instructed trials (both red or both green). After the rule targets appeared, the monkey had to maintain fixation for 300-500 ms. Then, the central spot was extinguished, cueing the monkey to make a saccade to one of the rule targets and foveate it for at least $200 \mathrm{~ms}$. In self-selected trials, because the rule targets differed in color, selection of a target established the rule for the rule implementation stage. In instructed trials, because the rule targets were the same color, it did not matter which target was selected; the rule was imposed on the monkey. Importantly, everything was the same in self-selected and instructed trials except that, in the former, the monkey selected the rule to use. If at any time during the rule selection stage, the monkey broke fixation by $>4^{\circ}$ before minimum duration times, made a saccade before cued to go, or failed to make a saccade, the trial was aborted and repeated later. Otherwise, the rule selection stage ended with disappearance of the rule targets and reappearance of the central white spot.

The rule implementation stage (Fig. $1 A$, right) then began as the monkey made a saccade to return to the central spot. After $400-600 \mathrm{~ms}$ of fixation, the monkey was presented with two square "decision targets" $8^{\circ}$ to the left and right. These targets could vary both in their size and brightness (see next paragraph for details). After another 500-1000 ms, the central spot disappeared and the monkey was required to make a saccade to one of the decision targets. If it selected the target consistent with the rule (e.g., the darker target when the rule was $R_{\mathrm{B}}$, "pick the darker target"), the trial was correct and the monkey received $0.25 \mathrm{ml}$ of 
A Rule-selection stage

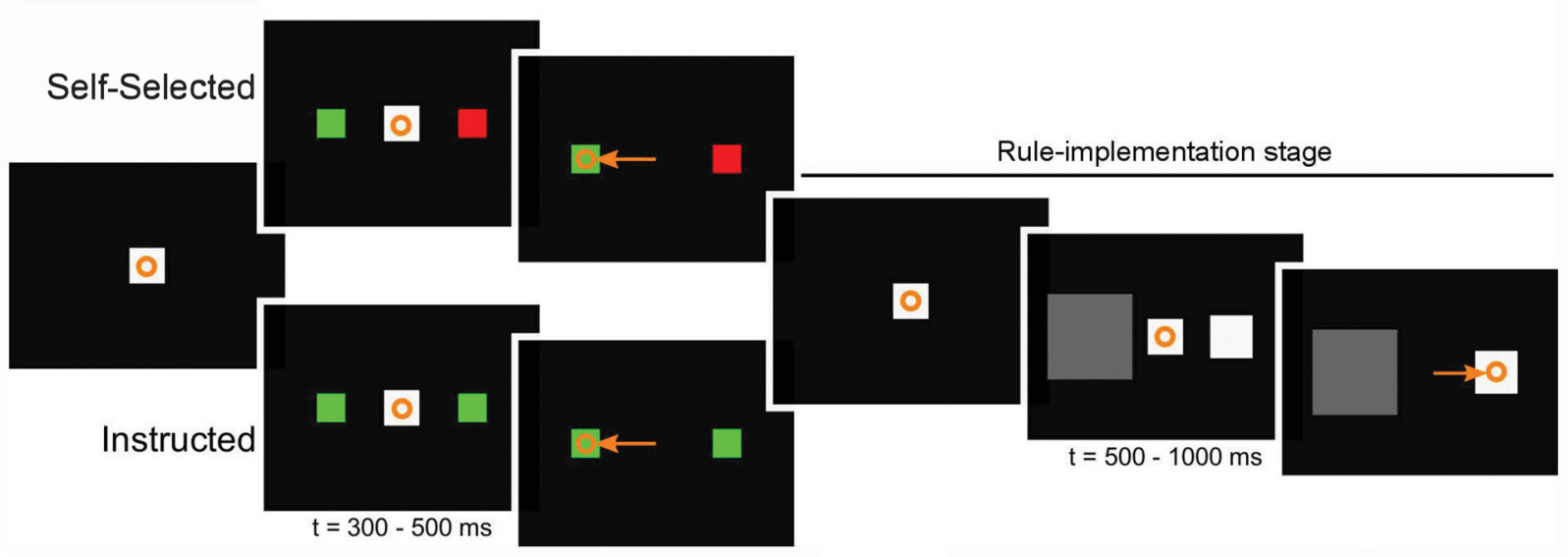

B

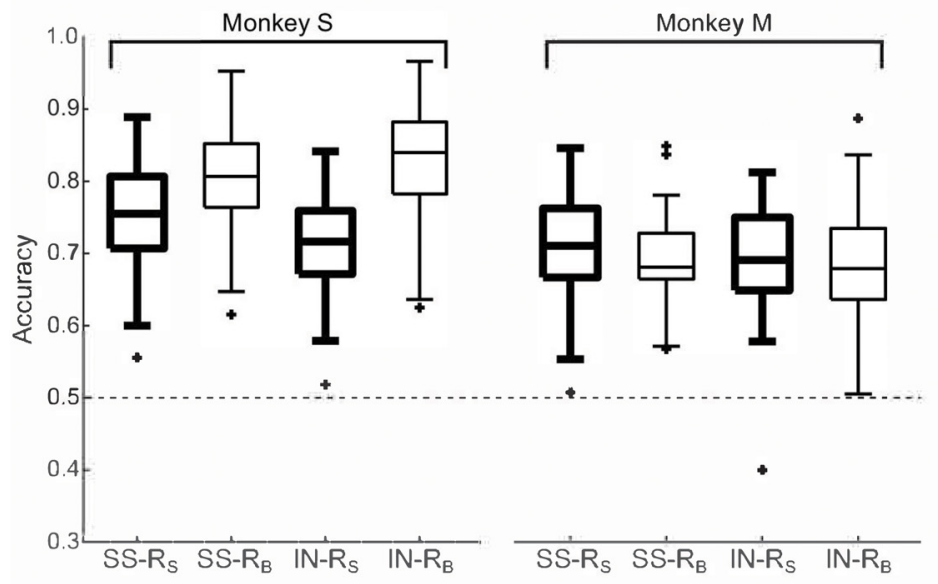

C

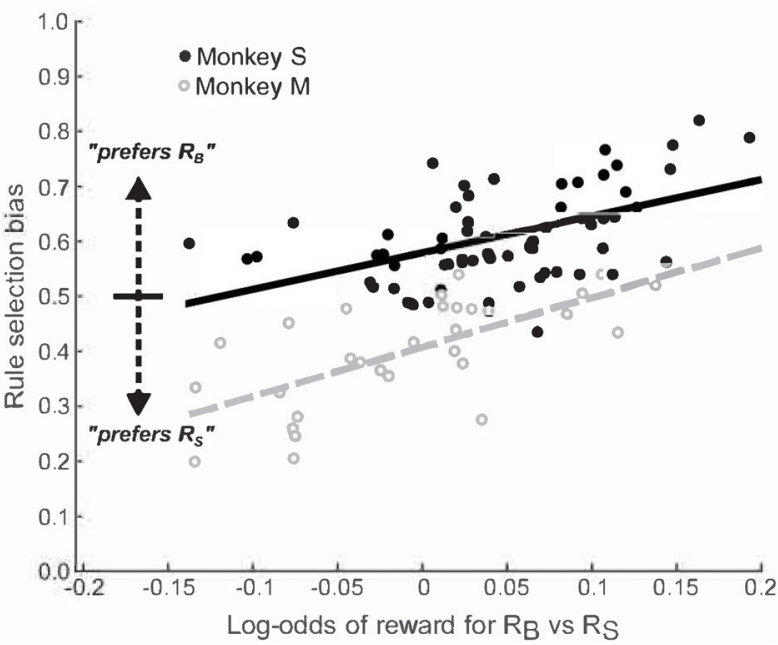

Figure 1. Task schematic and behavior. Orange symbols depict eye fixations (circles) and saccades (arrows). $A$, Each trial was divided into two stages. Left, Rule selection stage. A monkey looked at a fixation spot and two colored rule targets appeared in the periphery. Each color represented a learned, behavioral rule: $R_{\mathrm{S}}$ (pick the smaller target) or $R_{\mathrm{B}}$ (pick the darker target). In self-selected trials (top), the targets were of different colors and represented different rules. In instructed trials (bottom), the targets were the same color and represented the same rule. After a delay ( $t$, time), the monkey had to make a saccade to one of the targets, foveate it briefly, and then make a return saccade to the fixation spot. Right, Rule implementation stage. Two decision targets appeared, differing in their sizes and brightnesses. After a delay, the monkey had to select one of the targets with a saccade. If it picked the target concordant with the rule, then it received a reward. Shown is a successful $R_{\mathrm{s}}$ trial. Stimuli are depicted larger than in the experiment for clarity of illustration. $\boldsymbol{B}$, Accuracy on the task measured as fraction correct using data from recording sessions (Monkey S: $n=27$ sessions; Monkey M: $n=28$ sessions) and behavior-only sessions (Monkey S: $n=38$ sessions; Monkey M: $n=2$ sessions). Results are plotted separately for each animal (Monkey S, left; Monkey M, right). In each plot, data are separated by self-selected (SS; left) and instructed (IN; right) conditions and, within each condition, by rule $R_{\mathrm{S}}$ (bold lines) and rule $R_{\mathrm{B}}$ (thin lines). Accuracy was better than chance (horizontal dashed line) in all four cases for each monkey ( $t$ tests against 0.5 , all $p<0.0001$, corrected for multiple comparisons). Boxes extend from the 25 th to the 75 th percentiles of each set of samples and " +" symbols represent outliers. C, Session-by-session variation in rule selection biases. For each monkey, the amount of rule selection bias in a session was significantly and positively correlated with the log-odds of reward when using $R_{\mathrm{B}}$ versus $R_{\mathrm{S}}$ (Monkey $\mathrm{S}: r=0.531, p<0.0001$; Monkey M: $r=0.670, p<0.0001$ ). Lines show linear regression fits. Monkey S: black filled dots and solid line. Monkey M: gray unfilled dots and dashed line. Self-selected and instructed trials were combined. Data in $B$ and $C$ are used with permission from Abzug and Sommer (2018).

water or juice reward. If the monkey selected the wrong target, then the trial was an error and the monkey received no reward. If the monkey moved from fixation early or made a saccade to a nontarget location, then the trial was aborted, followed by a brief time-out before the start of a new trial.

The sizes of the decision targets were independently drawn from identical discrete uniform distributions on each trial (side lengths of $3^{\circ}, 3.5^{\circ}$, or $4^{\circ}$; also $4.5^{\circ}$ in some sessions). The brightnesses of the decision targets were also independently drawn from identical discrete uniform distributions $\left(1,5\right.$, or $15 \mathrm{~cd} / \mathrm{m}^{2}$; also $27 \mathrm{~cd} / \mathrm{m}^{2}$ in some sessions). Monkeys therefore were exposed to up to $4^{2}=16$ possible decision targets, $16^{2}=$ 256 possible pairs of decision targets, and $2 \times 256=512$ possible sets of decision targets and rule target combinations in each session. The central fixation point had a side length of $2^{\circ}$ and brightness of $27 \mathrm{~cd} / \mathrm{m}^{2}$ and the screen background had a brightness of $0.1 \mathrm{~cd} / \mathrm{m}^{2}$.
For most analyses, we were interested in the differences in size or brightness ( $\Delta S$ or $\Delta B$, respectively) between the targets rather than absolute sizes and brightnesses. Size and brightness scales have different ranges and brightness perception is nonlinear, so we used arbitrary size units (SU) defined as the difference between the ordinal ranks of the sizes of the decision targets (and analogously for brightness units, BU). The differences therefore varied between 0 and $3 \mathrm{SU}$ for size and $0-3 \mathrm{BU}$ for brightness, allowing for direct comparison of difficulty across both rules using ordinal rankings. More details of this methodology, including the use of SU and BU rankings in analyses of behavior during the task, can be found in Abzug and Sommer (2018).

We tailored the locations of rule targets to response fields in the SEF when possible, but the response fields are typically large and only a subset of cells exhibit directional tuning for visual or saccade-related activity (Schlag and Schlag-Rey, 1987; Russo and Bruce, 1996; Schlag-Rey et al., 
1997). We probed for evidence of tuning by having monkeys make visually guided saccades in eight directions (typically $10^{\circ}$ eccentricity) and then, if a best direction was found, in eight eccentricities at that best direction. In most recording sessions ( $64.7 \%, 44 / 68$ sessions), no optimal location was found, so we placed rule targets at locations (left and right on the horizontal meridian, $10^{\circ}$ eccentricity) similar to those of the decision targets (same but $8^{\circ}$ eccentricity). These locations were offset by $2^{\circ}$ to mitigate potential visual effects from the rule targets (e.g., afterimages) that might affect discrimination of the decision targets, even though such confounds were unlikely given that two saccades intervened before decision targets were presented (to a rule target and then back to central fixation). In the other sessions, an optimal location was found and it, plus the location diametrically opposite to it in the other visual field, was used for the rule targets $(35.3 \%, 24 / 68$ sessions). The optimal locations ranged from $5^{\circ}$ to $20^{\circ}$ eccentricity and $+74^{\circ}$ to $-45^{\circ}$ in angle from the horizontal meridian in contralateral space.

Analysis overview. We defined multiple epochs throughout the serial decision-making task and measured and analyzed the average firing rates within these epochs. There were four epochs during the rule selection stage (Fig. 1A, left). The baseline epoch began $500 \mathrm{~ms}$ before the fixation point appeared at the start of the trial and ended when the fixation point turned on. The fpacq epoch began when the fixation point was acquired and ended $300 \mathrm{~ms}$ after fixation had begun. The rulestim epoch began $50 \mathrm{~ms}$ after the colored rule targets appeared and ended $300 \mathrm{~ms}$ after target onset. The sacl epoch began $50 \mathrm{~ms}$ before the onset of the ruleselecting saccade and ended $150 \mathrm{~ms}$ after saccade onset.

There were three epochs of interest during the rule implementation stage (Fig. 1A, right). The refix epoch began $200 \mathrm{~ms}$ before the fixation point was reacquired to begin the rule implementation stage and ended $200 \mathrm{~ms}$ after the fixation point was reacquired. The percstim epoch began $50 \mathrm{~ms}$ after the decision targets appeared and ended $500 \mathrm{~ms}$ after target onset. The sac2 epoch began $50 \mathrm{~ms}$ before the onset of the ruleimplementing saccade and ended $150 \mathrm{~ms}$ after saccade onset.

There were also two reward-related epochs of interest, one before reward delivery and one after reward delivery. On all trials, the monkey needed to maintain fixation on the selected decision target for $200 \mathrm{~ms}$; after $200 \mathrm{~ms}$, all visual stimuli disappeared and reward was delivered if the decision was correct. Therefore, feedback (the presence or absence of reward) on all trials was reliably and predictably time-locked to saccade offset and we can consider the time point $200 \mathrm{~ms}$ after saccade offset to be the time of "potential reward delivery" on all trials regardless of trial outcome. The prerew epoch spanned from 150 to $50 \mathrm{~ms}$ before potential reward delivery. The postrew epoch spanned from 50 to $500 \mathrm{~ms}$ after potential reward delivery.

Preliminary screening. We recorded all well isolated neurons that we encountered. We selected neurons for further analysis based on two criteria: the neurons had to be task modulated and had to have been recorded during a sufficient number of behavioral trials. To determine task modulation, we ran a one-way ANOVA on the firing rate of each neuron individually ( $p<0.05$ criterion level) across each of the nine epochs of interest. We divided all behavioral trials into eight groups, representing all possible combinations of task condition (self-selected vs instructed), rule $\left(R_{\mathrm{S}}\right.$ vs $\left.R_{\mathrm{B}}\right)$, and outcome (correct vs error). If a neuron was recorded for at least eight trials in each of these eight sets of conditions (and was task modulated), we included it in the pool for analysis. In practice, $\sim 200$ total trials were required to satisfy this criterion. Of 163 recorded neurons, 155 neurons met these criteria.

Because making two linked decisions involves many events and potential behaviors, we subjected our data to a first-pass analysis to identify task variables that merited detailed study on the basis of their clear, consistent effects on neural activity. To do this, we ran an ANOVA on the firing rate of each neuron in each epoch individually ( $p<0.05$ criterion) across eight potential variables of interest: the task condition, the identity of the right rule target, the identity of the left rule target, the direction of the rule-selecting saccade, the rule, the location of the correct decision target, the direction of the rule-implementing saccade, and the trial outcome. We included a variable in further analyses if, in any epoch, there was a main effect of that task variable for more neurons than expected by chance $\left(11.61 \%\right.$ or $18 / 155$ neurons, cutoff determined from $\chi^{2}$ test at $p<0.05$ criterion). These procedures identified three variables for further analysis: the direction of the rule-selecting saccade, the rule, and the trial outcome.

Selectivity indices. To summarize how task variables modulated activity on a neuron-by-neuron basis, we used a selectivity index measure:

$$
\text { Selectivity index }=\left(\mathrm{FR}_{\mathrm{A}}-\mathrm{FR}_{\mathrm{B}}\right) /\left(\mathrm{FR}_{\mathrm{A}}+\mathrm{FR}_{\mathrm{B}}\right)
$$

where $\mathrm{FR}_{\mathrm{A}}$ is the neuron's mean firing rate on trials in behavioral condition $A$ and $\mathrm{FR}_{\mathrm{B}}$ is the mean firing rate on trials in behavioral condition $\mathrm{B}$. The selectivity indices corresponding to our three variables of interest were as follows:

$$
\begin{gathered}
\text { Direction selectivity index }=\left(\mathrm{FR}_{\text {contra }}-\mathrm{FR}_{\text {ipsi }}\right) /\left(\mathrm{FR}_{\text {contra }}+\mathrm{FR}_{\text {ipsi }}\right) \\
\text { Rule selectivity index }=\left(\mathrm{FR}_{\mathrm{RS}}-\mathrm{FR}_{\mathrm{RB}}\right) /\left(\mathrm{FR}_{\mathrm{RS}}+\mathrm{FR}_{\mathrm{RB}}\right) \\
\text { Outcome selectivity index }=\left(\mathrm{FR}_{\text {correct }}-\mathrm{FR}_{\text {error }}\right) /\left(\mathrm{FR}_{\text {correct }}+\mathrm{FR}_{\text {error }}\right)
\end{gathered}
$$

In order, conditions A and B for these indices were as follows: contralateral ("contra") versus ipsilateral ("ipsi”) direction; size rule ("RS") versus brightness rule ("RB"); and correct versus error trial outcomes. The sign of each selectivity index defined the relative preference of a neuron for condition A or B (e.g., directional selectivity was contralateral if the direction selective index was $>0$ ). The absolute value of each selectivity index defined the magnitude or "bias" of selectivity regardless of preference.

Normalization of population-averaged activity. To plot populationaveraged activity across subsets of our SEF population, we first normalized the activity of each neuron to its dynamic range within the epoch of interest. We subtracted off the minimum firing rate $y_{\min }$ and divided by the range $y_{\max }-y_{\min }$, yielding, for each neuron, a normalized firing rate that ranged from 0 to 1 . These normalized firing rates were then used to calculate population-averaged activity and the SEM across neurons.

Population dynamics. We used the multidimensional distance method of investigating population dynamics (Stokes et al., 2013). In short, the state of the full population was represented as a 155-dimensional vector in Euclidean space, where each dimension represents the instantaneous firing rate of a single neuron estimated within a $50 \mathrm{~ms}$ sliding window. The dynamic trajectory through this state space is the path that passes through the multidimensional coordinate of each time point.

In each epoch, for each neuron, we calculated the mean activity profile on correct and error trials. For each condition, we collected the individual time-varying neural responses and plotted them as a single trajectory through the 155-dimensional state space. Then, we calculated the Euclidean distance between trajectories for correct and error trials. To evaluate the significance of these time-varying distances using randomized permutation tests, we repeated the same process 1000 times but with randomly shuffled trial rule and outcome labels to generate a null distribution. Because distances are always positive, we normalized all distances by subtracting the median of the null distribution. Distances between trajectories were considered to be statistically significant when they exceeded the $99 \%$ confidence interval for the null distribution.

\section{Results}

\section{Behavior}

We investigated the neural basis of serial decision-making by recording from single neurons in SEF as monkeys selected a rule and then applied it to a visual discrimination. The monkeys' behavior during the task was reported in detail previously (Abzug and Sommer, 2018). To summarize, both monkeys performed the task well above chance using both self-selected and instructed rules, regardless of which task rule $\left(R_{\mathrm{S}}\right.$ vs $\left.R_{\mathrm{B}}\right)$ was in effect ( $t$ tests vs 0.5 , all $p<0.0001$, corrected for 8 multiple comparisons; Fig. $1 B)$. In self-selected trials, both monkeys exhibited session-bysession rule biases that correlated strongly with session-bysession fluctuations in accuracy when using each rule (Monkey S: $n=65$ sessions, $r_{(63)}=0.531, p<0.0001$; Monkey M: $n=30$ sessions, $r_{(28)}=0.670, p<0.0001$; Fig. $\left.1 C\right)$, consistent with purposeful rule selection for maximizing reward (Abzug and Som- 

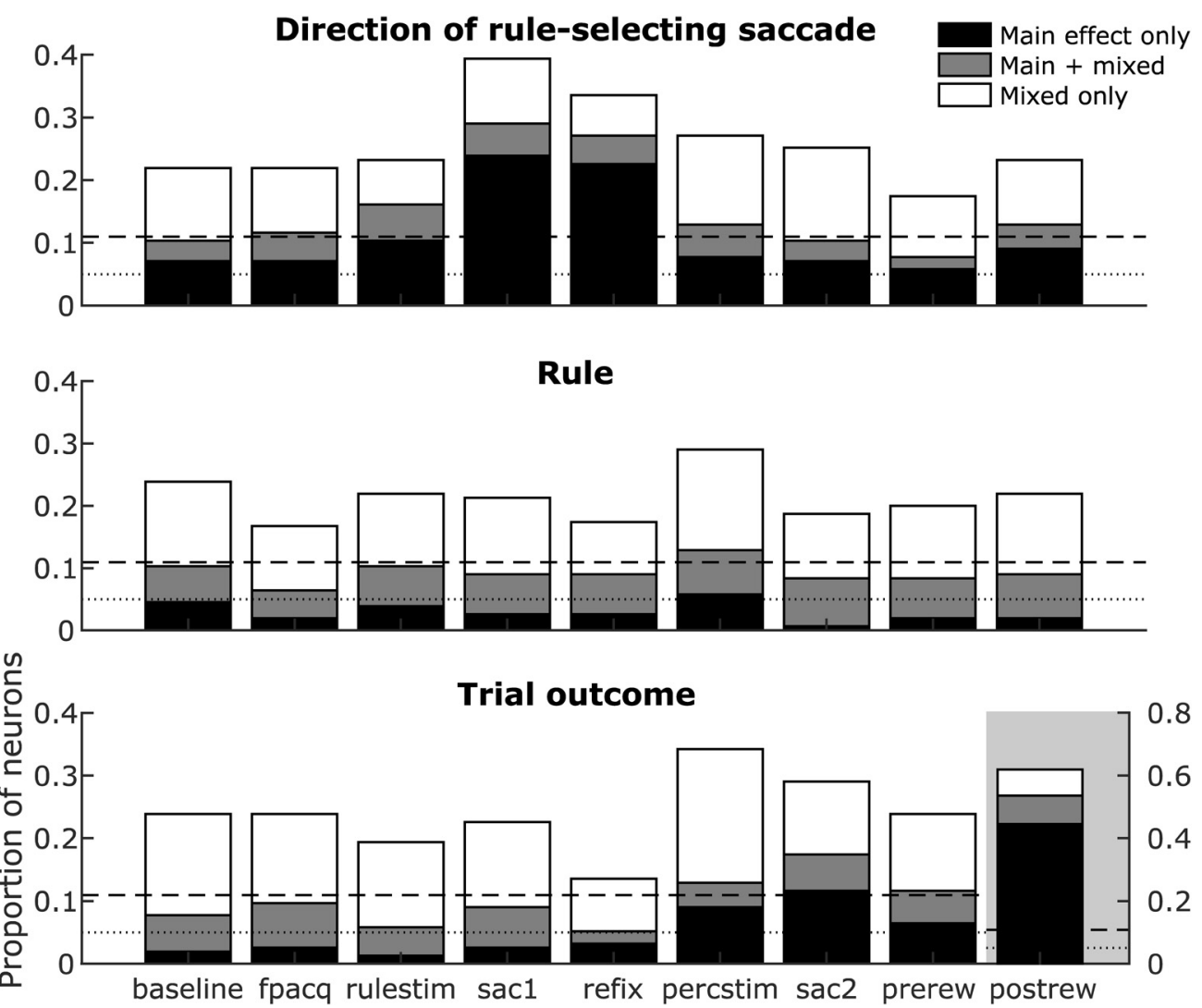

Figure 2. Summary of task-related activity modulations. Each set of graphs show the proportions of SEF neurons that exhibited significant main effects, mixed selectivity, or both for saccade direction (top), rule (middle), and trial outcome (bottom) in each task epoch. Dashed line represents the corrected significance cutoff for $n=155$ neurons (18/155 neurons or a proportion of 0.116 , determined by $\chi^{2}$ test). Dotted line represents the uncorrected significance cutoff $\alpha=0.05$. Note the different $y$-axis scale for trial outcome during the postrew epoch (gray background).

mer, 2018). Last, both monkeys had strong congruency effects and weak or nonexistent switching costs (for analyses, see Abzug and Sommer, 2018), consistent with results of previous studies of rule use in monkeys (Washburn, 1994; Stoet and Snyder, 2003; Avdagic et al., 2014). The monkeys therefore performed the task as expected, making serial decisions in a directed, rational way.

\section{Selectivity of SEF neurons: general}

The dataset consisted of 155 neurons recorded from the left SEF of the monkeys as they performed the serial decision-making task (Monkey S: 65 neurons; Monkey M: 90 neurons). Preliminary analyses demonstrated that three task variables, the direction of the rule-selecting saccade, the rule, and the trial outcome, modulated activity in significant fractions of the neurons (see "Preliminary screening" section in Materials and Methods). Of the task variables that did not show evidence of modulating SEF activity, the most striking negative result was for condition (selfselected vs instructed rules): no neuron in any epoch showed a main effect for this variable. Implications of this finding are addressed in the Discussion.

To study the effects of direction of rule-selecting saccades, rules, and trial outcomes in detail, we used a three-way ANOVA ( $p<0.05$ criterion) on SEF firing rates to look for main effects of the three variables and their two-way interactions. In this analysis, main effects quantify the selectivity of neural activity to each task variable, whereas interactions identify mixed selectivity to the variables. We found that many neurons exhibited selectivity and mixed selectivity for these task-relevant variables throughout the various task epochs (Fig. 2). There were three general patterns in the results. First, each task variable was encoded by a significant proportion of neurons in every epoch of the task (bars above dashed line in Fig. 2). Second, the task variables were encoded through main effects (black bars) as well as mixed selectivity with other task variables (white bars). Third, substantial proportions of neurons encoded the task variables through both main effects and mixed selectivity (gray bars). Therefore, the SEF neurons exhibited diverse patterns of selectivity and mixed selectivity for direction of the rule-selecting saccade, rule, and trial outcome. Analyses specific to each of these task variables are presented next.

\section{Selectivity of SEF neurons for saccade direction}

Building on the first task variable that modulated SEF activity, the direction of rule-selecting saccades, we analyzed the presence and properties of this modulation across our population of neurons (using firing rate epoch sac1; Fig. 3A). For comparison, we applied the same analyses to activity during the other two saccades in the task: the return saccade (using epoch refix; Fig. $3 B$ ) and the rule-implementing saccade (using epoch sac2; Fig. $3 C$ ). Of the 155 neurons analyzed, 45 individual neurons demonstrated directional selectivity for rule-selecting saccades (Fig. $3 A ; \chi^{2}$ test, $\left.\chi_{(1)}^{2}=31.15, p<0.0001\right)$. Similarly, 42 neurons demonstrated directional selectivity during the return saccade (Fig. $3 B ; \chi^{2}$ test, $\left.\chi_{(1)}^{2}=27.56, p<0.0001\right)$, and 22 neurons were directionally selective in both epochs. Directional preferences (calculated as the sign of the direction selectivity index) were approximately equally distributed between contraversive and ipsiversive (Fig. $3 A, B$, pie charts). 
A Rule-selecting saccade

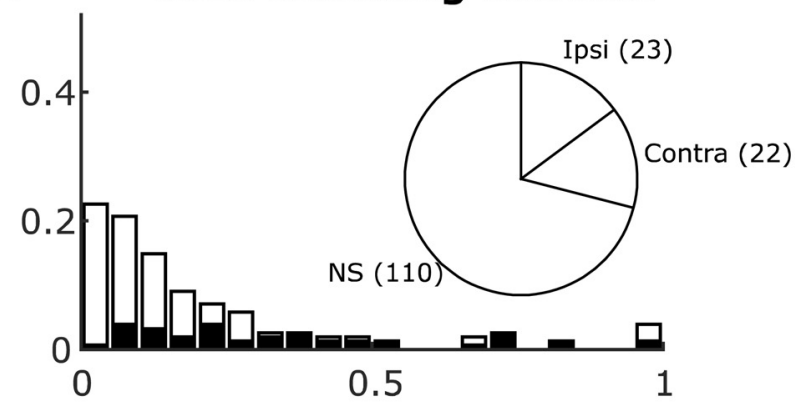

B Return saccade

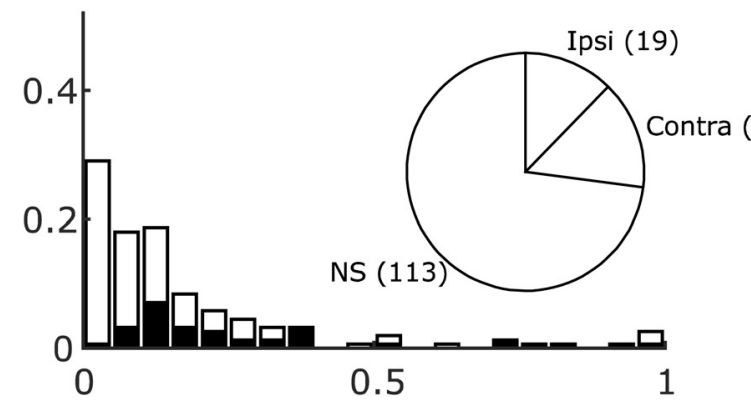

(23)

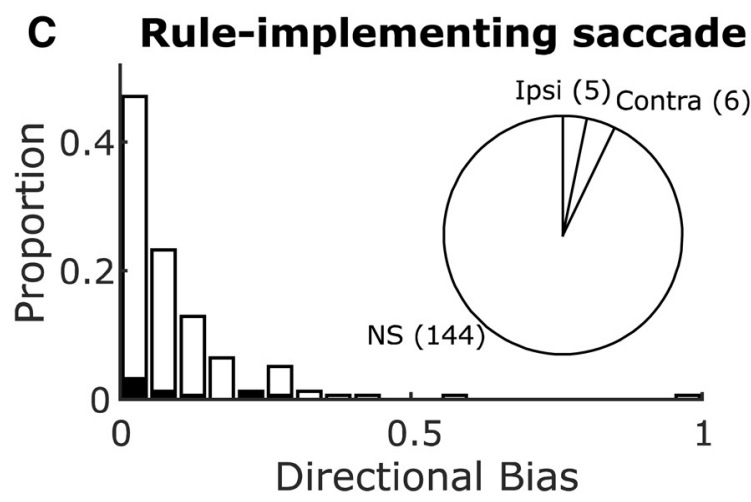

Figure 3. Directional selectivity for saccades in the SEF neurons. Pie charts show numbers of directionally selective neurons and their laterality (Ipsi, ipsilaterally selective; Contra, contralaterally selective) and nonselective (NS) neurons. Histograms show magnitudes of the neurons' significant (black) or nonsignificant (white) directional biases. Results shown separately for rule-selecting saccades (activity in sac1 epoch; $\boldsymbol{A}$ ), return saccades (refix epoch; $\boldsymbol{B}$ ), and ruleimplementing saccades (sac2 epoch; $\boldsymbol{C}$.

In contrast, directional selectivity for rule-implementing saccades occurred in only 11 neurons, failing to exceed the expected false positive level (Fig. $3 C ; \chi^{2}$ test, $\chi_{(1)}^{2}=0.50, p=0.477$ ). For these 11 neurons, directional preferences were split between contraversive and ipsiversive (Fig. 3C, pie chart). The strength of these preferences, measured as mean directional bias (absolute value of the direction selectivity index; Fig. $3 A-C$, histograms), was weak $(0.089 \pm 0.010)$, significantly lower than the directional bias of modulation for rule-selecting saccades or return saccades $(0.209 \pm 0.019$ and $0.176 \pm 0.017$, respectively; Wilcoxon ranksum tests, $U>19471, Z>4.69, p<0.0001$ for both).

The same results held for the subset of recordings (44/68 sessions) for which the vectors of all three types of saccades were closely matched due to similar locations of rule targets (horizontal meridian at $10^{\circ}$ eccentricity) and decision targets (horizontal meridian at $8^{\circ}$ eccentricity). For the 95 neurons recorded in these 44 sessions, directional selectivity was found in a significant proportion of neurons for rule-selecting saccades (32/95 neurons, $\chi^{2}$ test, $\left.\chi_{(1)}^{2}=24.47, p<0.0001\right)$ and return saccades (32/95 neurons; $\chi^{2}$ test, $\left.\chi_{(1)}^{2}=24.47, p<0.0001\right)$, but not for ruleimplementing saccades $\left(10 / 95\right.$ neurons; $\chi^{2}$ test, $\chi_{(1)}^{2}=1.81$, $p=0.179)$. Again, the mean directional bias during rule-implementing saccades $(0.090 \pm 0.010)$ was significantly weaker than during both rule-selecting and return saccades $(0.263 \pm 0.029$ and $0.221 \pm 0.026$, respectively; Wilcoxon rank-sum tests, $U>$ $6978, Z>4.65, p<0.0001$ for both).

Figure 4 shows data from an example neuron with saccaderelated activity from this subset of 95 neurons. Its activity was directionally selective for rule-selecting saccades (Fig. 4, left) and return saccades (Fig. 4, middle), but not for rule-implementing saccades (Fig. 4, right), even though the directions of all the saccades were identical (horizontal left and right) and amplitudes were comparable (means $9.97 \pm 0.041^{\circ}$ for rule-selecting saccades, $9.78 \pm 0.040^{\circ}$ for return saccades, and $7.78 \pm 0.014^{\circ}$ for rule-implementing saccades). Across the 44 sessions in which the 95 neurons were recorded, the distributions of saccade amplitudes were $9.58 \pm 0.093^{\circ}$ for rule-implementing saccades, $9.31 \pm$ $0.093^{\circ}$ for return saccades, and $7.55 \pm 0.061^{\circ}$ for rule-implementing saccades, calculated using mean amplitudes from each session. Although these distributions were significantly different (one-way repeated-measures ANOVA on mean saccade amplitude, main effect of saccade type, $\left.F_{(2,86)}=2295, p<0.0001\right)$, the effect sizes were very small (rule-implementing saccades were only $2.03^{\circ}$ shorter than rule-selecting saccades and $1.76^{\circ}$ shorter than return saccades) compared with the large sizes of SEF response fields that typically span a quadrant or more, when they can be delimited at all (Schlag and Schlag-Rey, 1987; Russo and Bruce, 1996; Schlag-Rey et al., 1997). Therefore, whereas we cannot rule out an effect of saccade vector on decreased directional selectivity for rule-implementing saccades, the more prominent difference was contextual: rule-implementing saccades were used for perceptual discrimination, but the other saccades were not.

\section{Selectivity of SEF neurons for rules}

As demonstrated with the three-way ANOVA analysis and as shown in Figure 2 (middle), a main effect of rule (alone or with mixed selectivity) was found in a significant proportion of SEF neurons only during the percstim epoch (20/155 neurons, $\chi^{2}$ test, $\left.\chi_{(1)}^{2}=5.65, p=0.017\right)$, when the stimuli for the visual discrimination were presented. This was the point in the task when the monkey had to integrate the rule with the trial-specific decision targets to generate its decision and the appropriate motor plan. A representative neuron is shown in Figure $5 A$. In the 20 neurons with rule selectivity during the percstim epoch, rule preferences (sign of the rule selectivity index) were equally distributed (Fig. $5 B$, pie chart) and rule biases (absolute value of the rule selectivity index) were modest, averaging $0.110 \pm 0.018$ (Fig. $5 B$, histogram). Task rules were not encoded by a significant proportion of neurons in any other epoch, including during the sacl epoch when the rule was selected (14/155 neurons, $\chi^{2}$ test, $\chi_{(1)}^{2}=1.76$, $p=0.185)$ or during the refix epoch when the rule needed to be held in memory ( $14 / 155$ neurons, $\chi^{2}$ test, $\left.\chi_{(1)}^{2}=1.76, p=0.185\right)$. Therefore, the analysis provided no evidence for continuous encoding from rule selection to application in the SEF neuronal population; rules were represented only when they were needed, at the time of decision target presentation.

Although there was a lack of continuous signaling from rule selection to implementation, another form of continuity would be if individual neurons participated similarly in both events. To test this, we focused on the 45 neurons with significant directional selectivity during the sacl epoch. We found that the mag- 

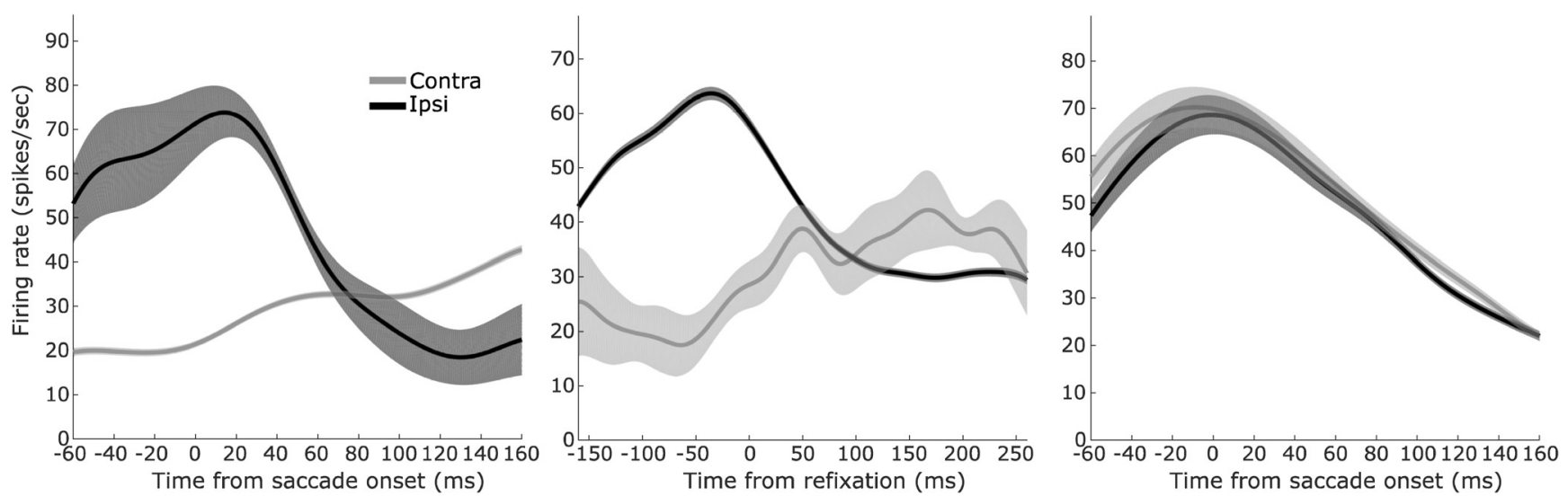

Figure 4. Activity of an example SEF neuron conditioned on saccade direction, around the times of the rule-selecting saccade (left), the refixation saccade (center), and the rule-implementing saccade (right). Spike density functions used Gaussian kernels of $\sigma=20 \mathrm{~ms}$ (MacPherson and Aldridge, 1979). The neuron exhibited perisaccadic modulations for all three saccades, but the modulations were directionally sensitive only for rule-selecting and refixation saccades. Shaded error bars are SEM across trials within each condition.

A

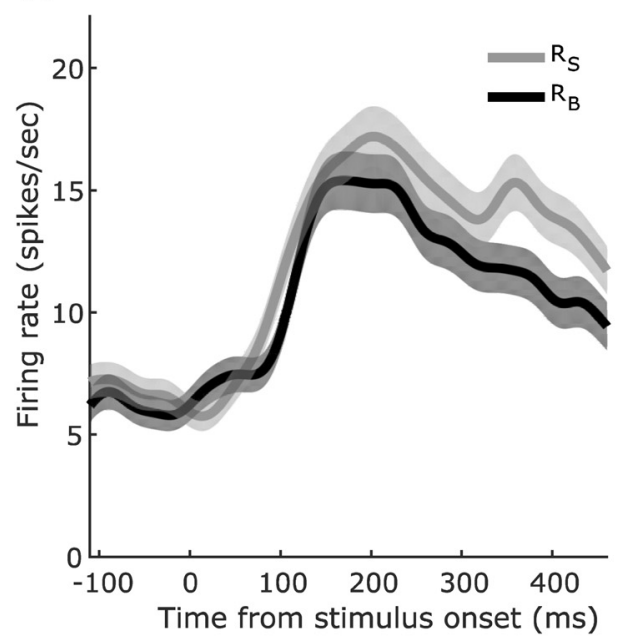

B

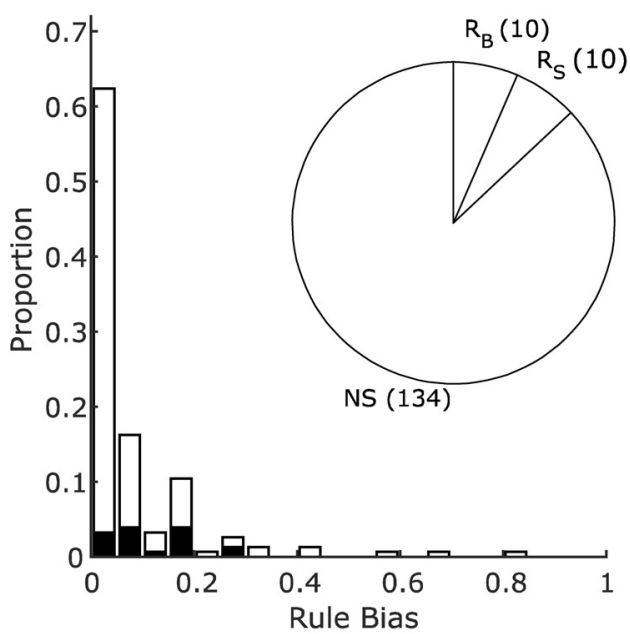

Figure 5. Selectivity for task rules in the SEF neurons. $A$, Activity of an example SEF neuron conditioned on task rule during the percstim epoch. The neuron fired more when the size rule $R_{\mathrm{S}}$ was in effect, with the difference in firing emerging $\sim 300 \mathrm{~ms}$ after decision target onset. Conventions are as in Figure 4 . $\boldsymbol{B}$, Pie chart showing the numbers of rule selective neurons and their preference (rule $R_{\mathrm{S}}$, rule $R_{\mathrm{B}}$, or NS, nonselective). Histogram shows magnitudes of the neurons' significant (black) or nonsignificant (white) rule selectivity biases.

nitude of that selectivity was correlated with the magnitude of the neurons' rule selectivity in the later percstim epoch across these neurons (Spearman's $r_{(43)}=0.355, p=0.017$ ). As an internal control, we repeated the test for the same neurons using the magnitude of directional selectivity during the sac2 epoch, but that correlation was not significant (Spearman's $r_{(43)}=0.202, p=$ 0.183 ). Because data from the percstim epoch were tested twice, significance levels were corrected to $p<0.025$. Also, for these analyses, we used the absolute values of the numerators of the rule and direction selectivity indices to minimize the contributions of condition-invariant neuronal properties (e.g., dynamic range) and focus on condition-dependent changes in firing. The sac1-percstim correlation of selectivity measures suggests that individual SEF neurons contribute serially to rule selection and implementation, although they encode different signals at each stage (saccade direction then rule).

Last, given that both monkeys were behaviorally biased toward selecting the rule that was more likely to result in reward (Fig. 1C; Abzug and Sommer, 2018), we investigated whether neural activity during a trial could predict a monkeys' future rule selections. No epochs of SEF activity, however, were associated with rule selection during the subsequent trial (maximum across task epochs $=8 / 155$ neurons, $\chi^{2}$ test, $\left.\chi_{(1)}^{2}=0, p=1.0\right)$, even when restricting the analysis only to subsequent self-selected trials (maximum 11/155 neurons, $\chi^{2}$ test, $\chi_{(1)}^{2}=0.50, p=0.478$ ). Although this does not rule out a contribution of SEF to biases in rule selection that track performance, a key indicator of rational serial decision-making behavior (Abzug and Sommer, 2018), at the single-neuron level, we found no evidence for such signals.

\section{Selectivity of SEF neurons for trial outcome}

In our task, the three-way ANOVA analysis revealed a main effect of trial outcome (alone or with mixed selectivity) in a significant proportion of SEF neurons starting from the appearance of the decision targets through reward (Fig. 2); specifically, in the percstim epoch $\left(20 / 155, \chi^{2}(1)=5.65, p=0.017\right)$, sac2 epoch $(27 /$ $\left.155, \chi^{2}(1)=11.63, p=0.0006\right)$, prerew epoch $\left(18 / 155, \chi^{2}(1)=\right.$ $4.20, p=0.04)$, and postrew epoch $\left(83 / 155, \chi_{(1)}^{2}=87.50, p<\right.$ $0.0001)$. Many of the neurons encoded trial outcome prospectively during the percstim, sac2, and prerew epochs, even though the animal had not yet received feedback. Such neurons were approximately equally likely to fire more during correct trials and 

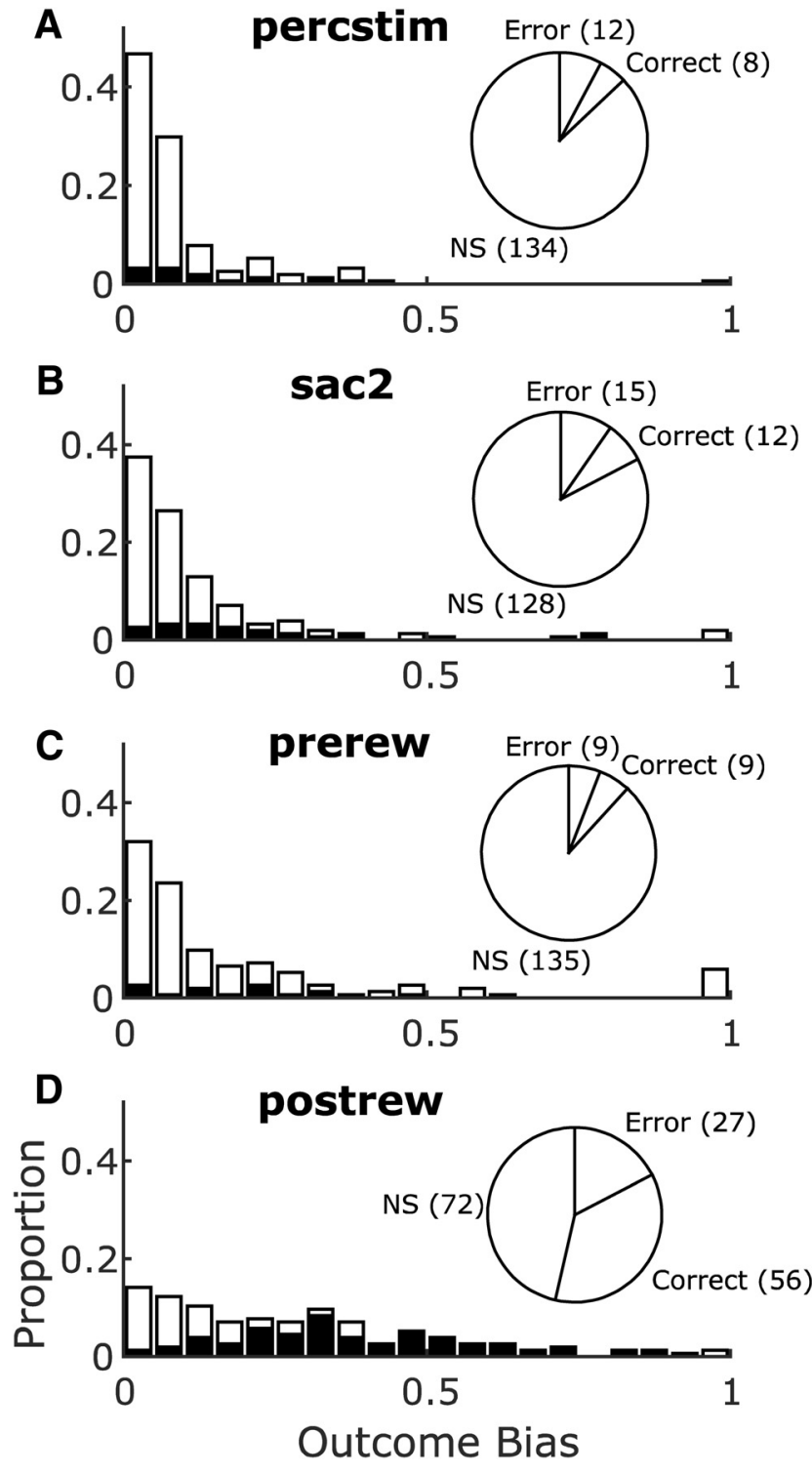

Figure 6. Selectivity for trial outcomes in the SEF neurons. Pie charts show numbers of outcome selective neurons and their preference (correct trials, error trials, or NS, nonselective). Histograms show magnitudes of the neurons' significant (black) or nonsignificant (white) outcome selectivity biases. Results shown separately for the percstim epoch $(\boldsymbol{A})$, the sac2 epoch $(\boldsymbol{B})$, the prerew epoch $(\boldsymbol{C})$, and the postrew epoch $(\boldsymbol{D})$.

error trials (signs of the outcome selectivity index in each epoch; pie charts in Fig. $6 A-C$ ). In contrast, neurons that encoded trial outcome after feedback, in the postrew epoch, were significantly more likely to fire more after correct trials (i.e., firing more in response to reward; $n=56$ neurons) than error trials (i.e., firing more in response to the lack of reward; $n=27$ neurons; $\chi_{(1)}^{2}=$ 20.26, $p<0.0001$; pie chart in Fig. 6D).

During the percstim epoch, when the subject could integrate rule information with the decision targets and begin to formulate its decision, neuronal firing rates for outcome-sensitive neurons began to diverge 100-200 ms after target onset, with activity in the correct-preferring neurons (Fig. 7A) diverging slightly before activity in the error-preferring neurons (Fig. $7 B$ ). Both sets of neuronal modulations were caused by increases in firing for the preferred outcome (whereas firing rates for the nonpreferred outcome remained approximately constant). In contrast, most neurons that encoded trial outcome after feedback showed mod- ulated firing rates predominantly on error trials regardless of whether the neuron preferred correct trials (Fig. 8A; correct preference manifested as a decrease in firing for error trials) or errors (Fig. 8B; error preference manifested as an increase in firing for error trials).

To determine whether this outcome encoding was truly being driven by prospective/detected outcome or could be explained by the sensory characteristics of the decision target, we first ran the following multiple linear regression on neuronal firing rate in each epoch:

$$
\begin{aligned}
y=\beta_{0}+\beta_{1} R+ & \beta_{2} \Delta S+\beta_{3}|\Delta S|+\beta_{4} \Delta B+\beta_{5}|\Delta B| \\
& +\beta_{6} R \Delta S+\beta_{7} R|\Delta S|+\beta_{8} R \Delta B+\beta_{2} R|\Delta B|
\end{aligned}
$$

where $y$ is the firing rate, $R$ is the rule in effect $\left(0\right.$ for $R_{\mathrm{S}}, 1$ for $\left.R_{\mathrm{B}}\right)$, $\Delta S$ is the difference in size between the decision targets, and $\Delta B$ is the difference in brightness between the decision targets (see "Serial decision-making task" section in Materials and Methods for details). We included the unsigned differences in the model (i.e., $|\Delta S|$ and $|\Delta B|)$ to compensate for the potential encoding of task difficulty. We also included interactions of all terms with the rule $R$ in case sensory variables were encoded in a functional manner (e.g., larger difference in the chosen/unchosen dimension) in addition to a purely sensory manner (e.g., larger difference in the size/brightness dimension). We then took the residuals of this model, which represent the portion of neural activity unaccounted for by the sensory and sensory-related variables contained therein, and investigated whether those residuals encoded trial outcome.

As with our previous results, we found that a significant proportion of SEF neurons encoded trial outcome in those same epochs even after controlling for other potential explanatory variables: percstim $\left(23 / 155, \chi_{(1)}^{2}=8.06, p=0.0045\right)$, sac2 (28/ $\left.155, \chi_{(1)}^{2}=12.57, p=0.0004\right)$, prerew $\left(20 / 155, \chi_{(1)}^{2}=5.65, p=\right.$ $0.017)$, and postrew $\left(104 / 155, \chi_{(1)}^{2}=128.83, p<0.0001\right)$. This was not the case for any of the other task epochs (all $p \geq 0.13$ ).

We also analyzed the population dynamics for outcome encoding throughout the trial (Fig. 9) by calculating the multidimensional distance between population firing rates in 155dimensional space (see "Population dynamics" section in Materials and Methods for details). During the first half of the trial (Fig. 9, baseline through refix epochs), trial outcome signals were insignificant except for very brief periods $(27 \mathrm{~ms}$ at the longest). Trial outcome signals became prominent, however, after decision target onset (Fig. 9, percstim epoch), including a stretch of continuous, significant signal for $102 \mathrm{~ms}$. The timing of that signal, from 205-307 ms after decision target onset, reflected the temporal interval for outcome encoding shown in Figure 7. Trial outcome encoding emerged again when the rule implementation saccade was made (Fig. 9, sac2) and leading up to feedback (Fig. 9, prerew). After feedback (delivery or withholding of reward), the trial outcome signal became extremely strong and long-lasting (Fig. 9, postrew; note change of $y$-axis scale).

\section{Persistent effect of past trial outcomes}

Immediately after feedback, in the postrew epoch, approximately half of the SEF neurons encoded trial outcome (Fig. 10A; 83/155 neurons, $\left.\chi_{(1)}^{2}=87.50, p<0.0001\right)$. How long did that signal persist? We analyzed this for each neuron using five-way ANOVAs on firing rates in each epoch as a function of the outcomes of the current trial " $n$ " (to control for outcome effects described above) and the four previous trials $(n-1$ through $n-$ 4). A main effect of a previous trial ( $p<0.05$ criterion) indicated 
A

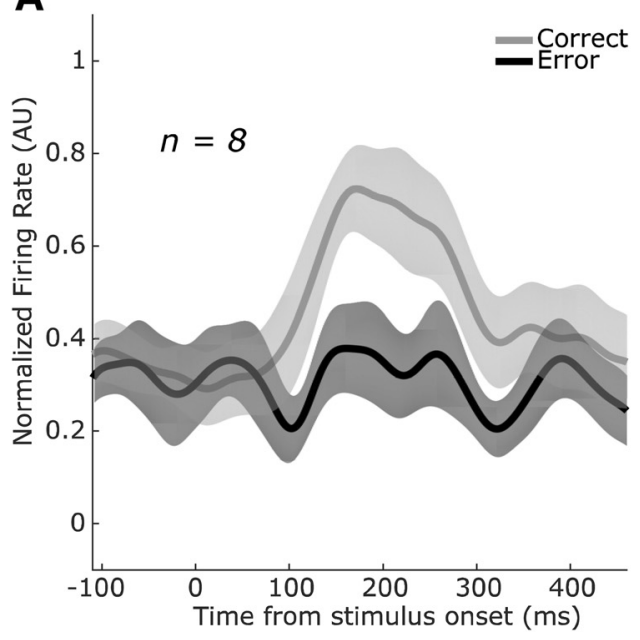

B

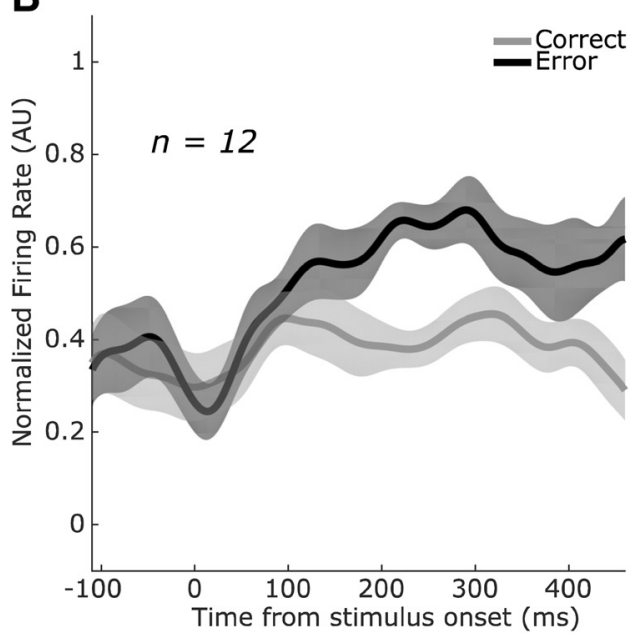

Figure 7. Population-averaged trial outcome selectivity during the percstim epoch. $A$, SEF neurons that fired preferentially on correct trials during the percstim epoch $(n=8)$ exhibited phasic modulations $100-300 \mathrm{~ms}$ after appearance of the decision targets. $\boldsymbol{B}$, In contrast, neurons that fired preferentially on error trials during the percstim epoch $(n=12)$ showed more tonic modulations beginning $\sim 150 \mathrm{~ms}$ after appearance of the decision targets and, in some cases, lasting throughout the remainder of the trial. Conventions are as in Figure 4 except that shaded error bars are SEM across neurons within each subpopulation.

A

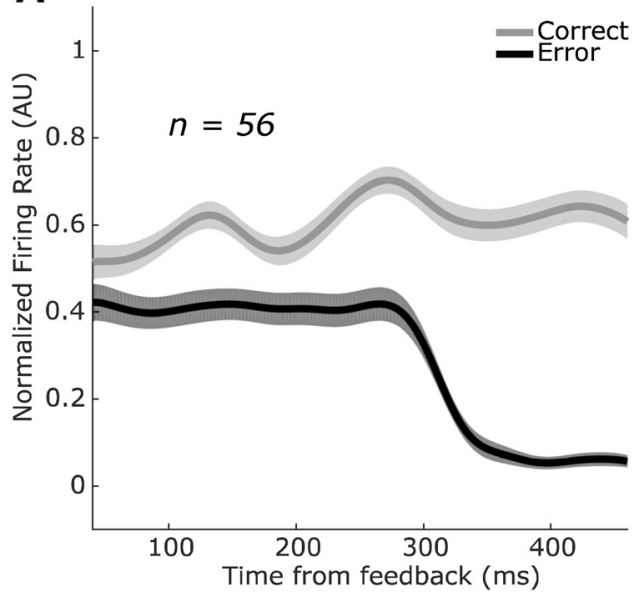

B

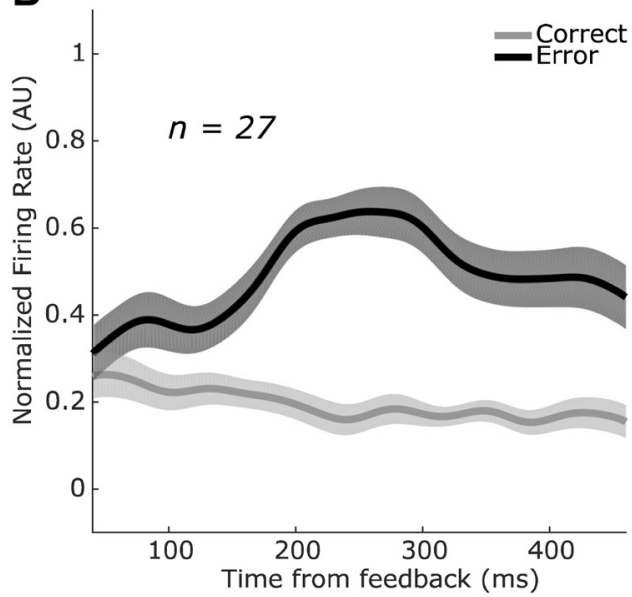

Figure 8. Population-averaged trial outcome selectivity during the postrew epoch. $\boldsymbol{A}$, SEF neurons that fired preferentially on correct trials during the postrew epoch ( $n=56)$ showed, on average, a cessation of firing $\sim 300 \mathrm{~ms}$ after the absence of reward in error trials. $\boldsymbol{B}$, Neurons that fired preferentially on error trials during the postrew epoch ( $n=27)$ showed, on average, an elevation in firing after absence of reward in error trials. Shaded error bars are SEM across neurons within each subpopulation.

that its outcome influenced the neuron's activity in the tested epoch. We found that, for many SEF neurons, selectivity for past trial outcomes lasted into and through the subsequent trials (Fig. $10 B)$. At the start of trial $n, 38 / 155$ neurons encoded the outcome of trial $n-1$ during the baseline epoch $\left(\chi_{(1)}^{2}=22.97, p<0.0001\right)$ and 19/155 during initial fixation (fpacq epoch; $\chi_{(1)}^{2}=4.91, p=$ $0.027)$. Then, the proportion dropped below the false-positive level (0.116, cf. Fig. 2, dashed line) for the rest of the trial. During the baseline epoch, a significant proportion of neurons even encoded the outcome of trial $n-2\left(20 / 155, \chi_{(1)}^{2}=5.65, p=0.017\right)$, but after that, the persistence of the signal ceased. As with prospective and proximate outcome-encoding neurons, neurons that encoded past trial outcomes could prefer either previous correct trials (Fig. 11A) or error trials (Fig. 11B). In our task, therefore, SEF activity was influenced by previous trial outcomes, with the outcome signal returning transiently even after an intervening trial.

\section{Mixed selectivity in the SEF population}

Given the patterns of direction, rule, and outcome selectivity observed in our SEF population, we then investigated whether the mixed selectivity might represent behaviorally relevant interactions. Specifically, we were interested in the interaction between rules and outcomes because this mixed selectivity could provide the teaching signal necessary to dynamically modulate rule selections to maximize rewards. We found that a significant proportion of SEF neurons encoded the interaction between the rule and anticipated outcome during both the percstim epoch $\left(25 / 155, \chi_{(1)}^{2}=9.80, p=0.002\right)$ and prerew epoch $\left(21 / 155, \chi_{(1)}^{2}=\right.$ $6.43, p=0.012)$. However, the SEF population did not encode the interaction between the rule and outcome after the outcome was observed (postrew epoch: 17/155, $\chi_{(1)}^{2}=3.52, p=0.06$; baseline epoch of next trial: $\left.12 / 155, \chi_{(1)}^{2}=0.86, p=0.36\right)$. Likewise, the interaction between rule and outcome was not encoded during the subsequent trial's sacl epoch, when it could have 

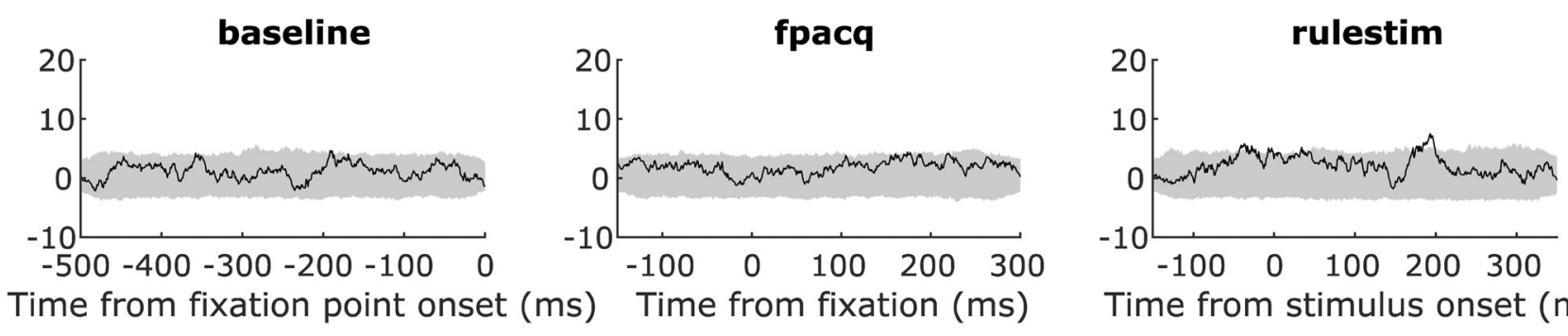

Time from fixation point onset (ms) Time from fixation (ms)

Time from stimulus onset (ms)
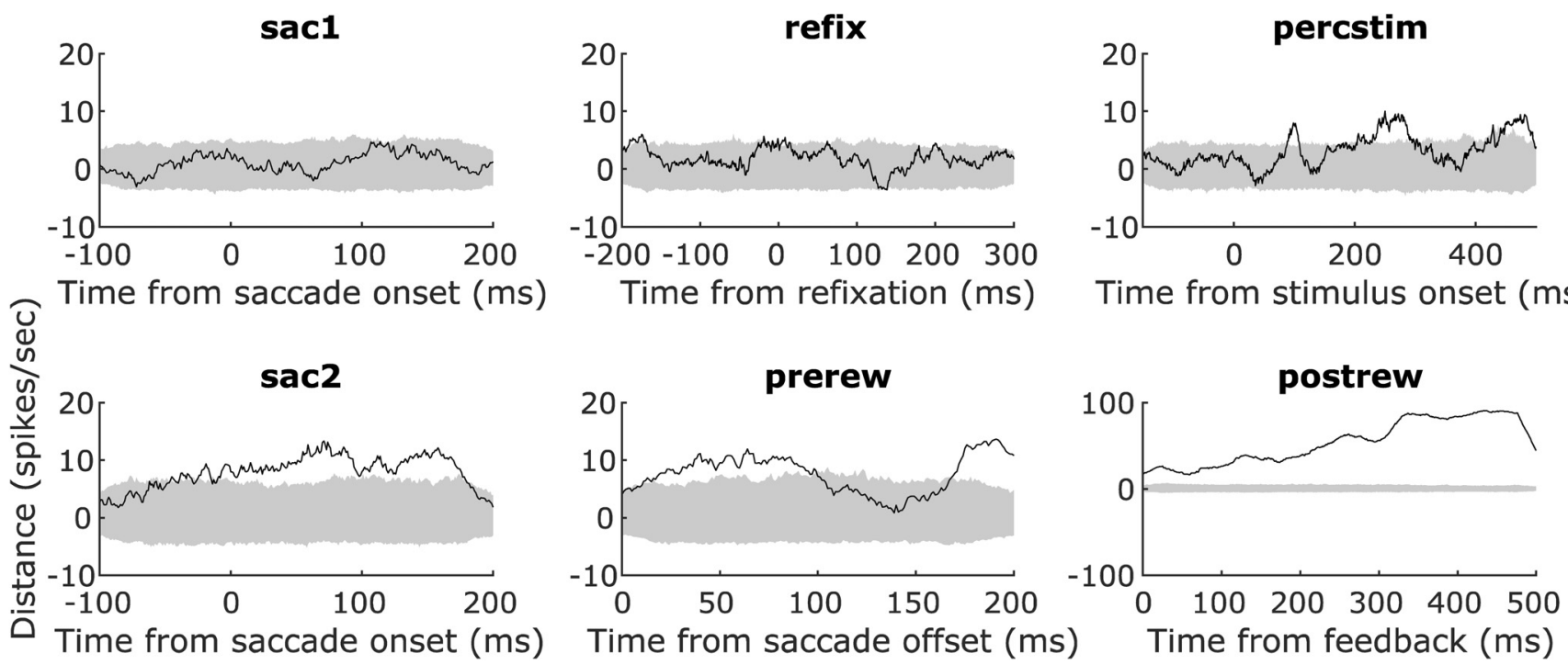

Figure 9. Population dynamics of trial outcome encoding. Time courses calculated using the multidimensional distance (Stokes et al., 2013) between neuronal trajectories on correct and error trials. Distances (solid black lines) were significant when they exceeded the $99 \%$ confidence interval (gray shaded area) of the null distribution (see "Population dynamics" section in Materials and Methods for more details). Significant, strong trial outcome signals appeared after onset of the decision targets (percstim), persisted during (sac2) and after (prerew) the rule-implementing saccades, and peaked after feedback (postrew; for this, note the different $y$-axis scale).
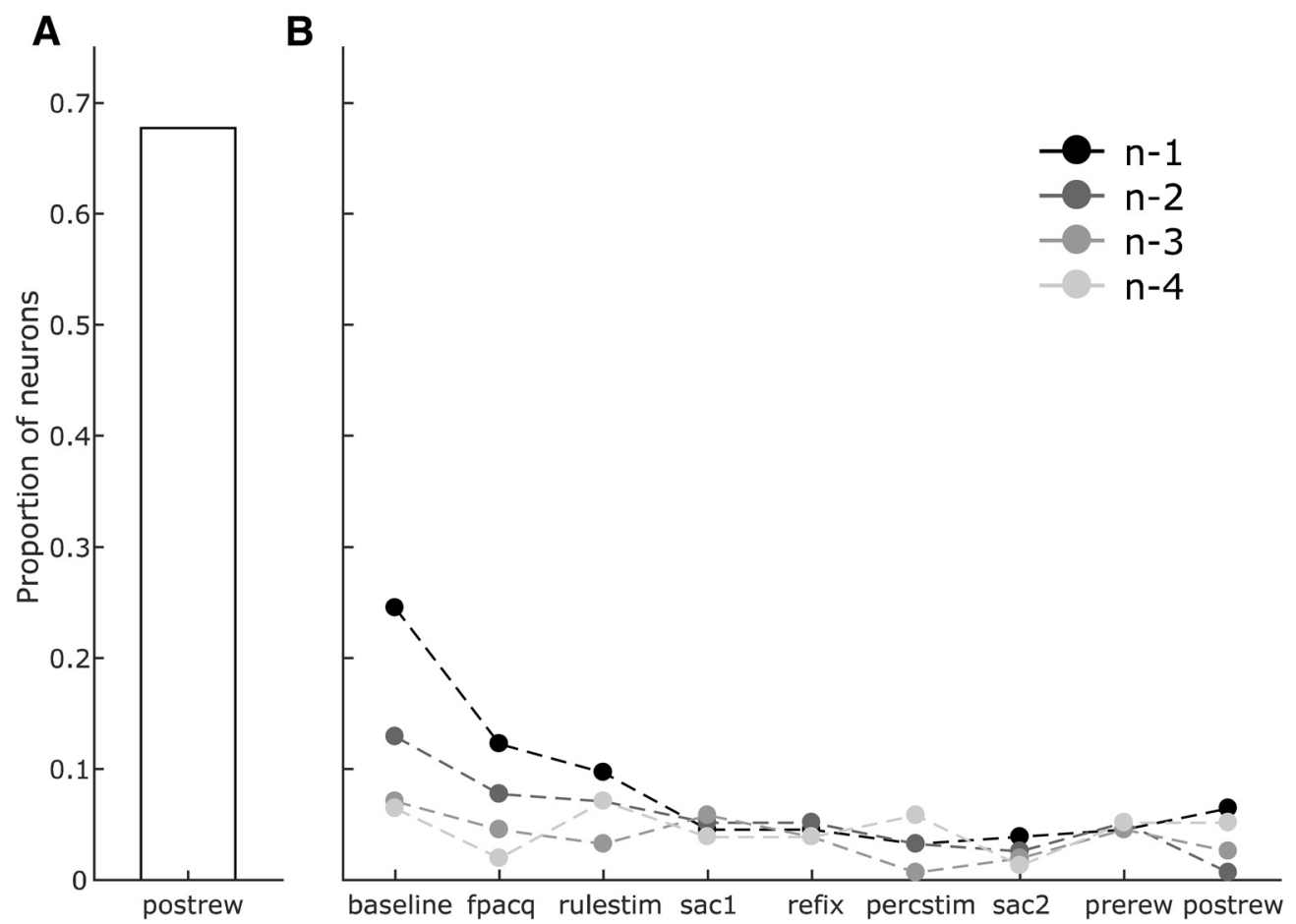

Figure 10. Persistent effect of past trial outcomes in the SEF neurons. $\boldsymbol{A}, \mathrm{A}$ large proportion of neurons encode trial outcome immediately after feedback delivery (postrew epoch). $\boldsymbol{B}$, This outcome-encoding persisted in 38/155 neurons $(p<0.0001$ ) at the start of the subsequent trial (baseline and fpacq epochs, trial $n-1)$. The number of neurons encoding trial outcome dropped toward chance (proportion $=0.116$ ) during the remainder of the trial, but rebounded again during the baseline period of the next trial (baseline epoch, trial $n-2 ; 20 / 155$ neurons, $p=0.017$ ). Beyond that, effects of past trial outcomes became nonsignificant. 

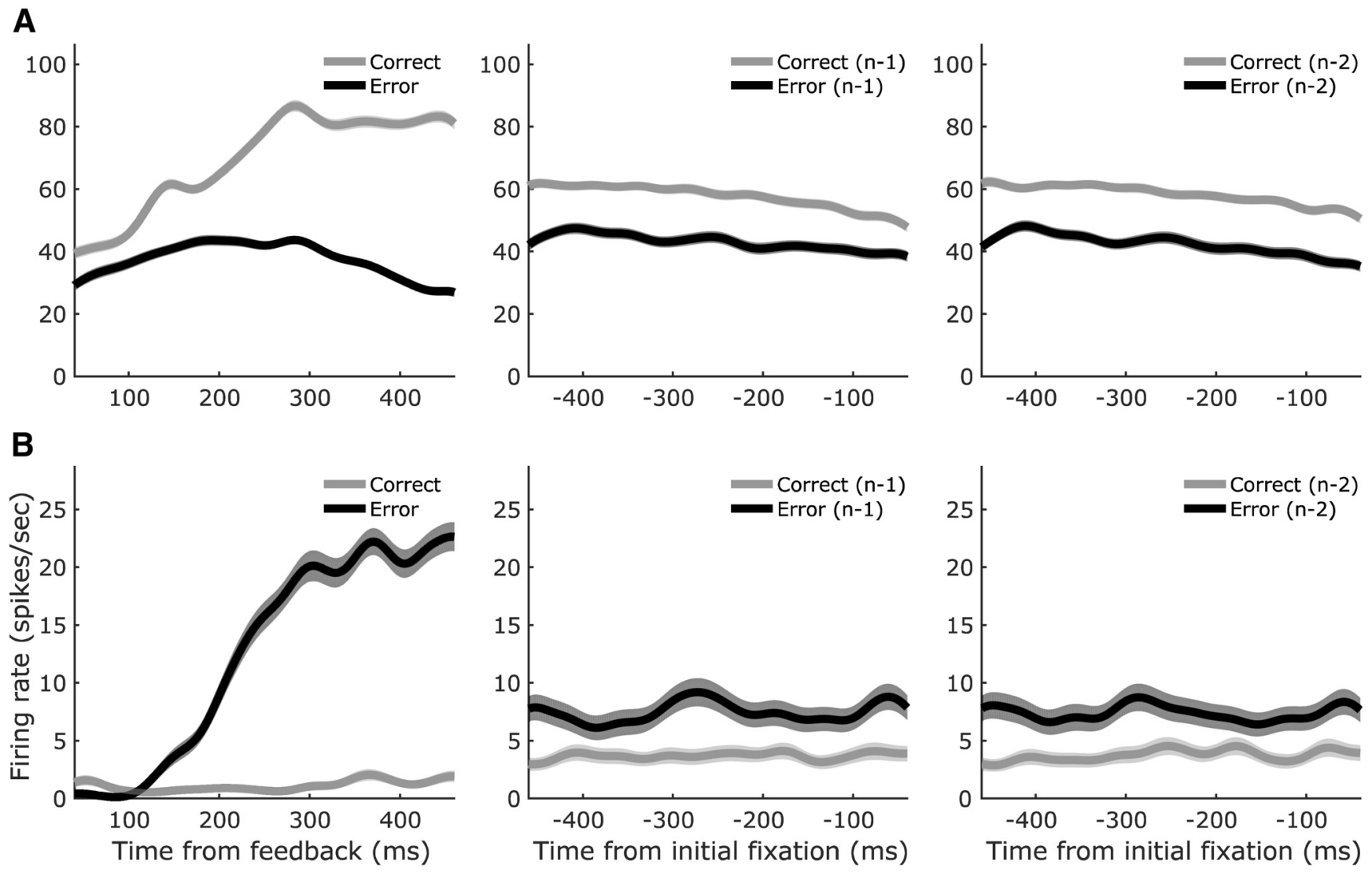

Figure 11. Activity patterns of example SEF neurons that encoded past trial outcomes. $\boldsymbol{A}$, Neuron that fired more after correct trials. $\boldsymbol{B}$, Neuron that fired more after error trials. Both neurons showed large modulations in firing rate immediately after feedback delivery (postrew epoch, left). These tonic modulations persisted into the start of the next trial (baseline epoch, trial $n-1$, center) and were still present at the start of the trial after that (baseline epoch, trial $n-2$, right). Shaded error bars are SEM across trials within each condition.

potentially served to guide optimal rule selection $\left(11 / 155, \chi_{(1)}^{2}=\right.$ $0.50, p=0.48$ ).

\section{Discussion}

We recorded from neurons in the SEF while monkeys performed a serial decision-making task requiring them to use selected or instructed rules to perform a visual discrimination. The neurons exhibited malleable directional selectivity and, supporting our first hypothesis, activity related to key events of the task: "just-intime" encoding of task rules and robust encoding of trial outcomes both before and after feedback was delivered. We found no evidence, however, for our second hypothesis of sustained activity between the two decisions of the task. SEF neurons appear to be engaged with the task of selecting then applying rules in temporally discontinuous and somewhat unexpected ways.

\section{Directional selectivity}

Prior studies reported that directionally selective activity in SEF is task dependent (Mann et al., 1988; Olson and Gettner, 1995, 1999; Purcell et al., 2012). Furthermore, inactivation of SEF tends to lead to spatially balanced, bilateral deficits (Schiller and Chou, 1998; Sommer and Tehovnik, 1999), in contrast to the strong contralateral impairments observed for inactivation of the nearby FEF (Sommer and Tehovnik, 1997; Schiller and Chou, 1998; Dias and Segraves, 1999; Chafee and Goldman-Rakic, 2000). We found that the directional selectivity of SEF saccaderelated activity changed within our task depending on the purpose of the saccade. The occurrence and strength (bias) of directional selectivity was much greater for saccades that selected rules and returned to fixation than for saccades that reported a perceptual discrimination. Together, the prior and current results suggest that SEF does not play a role in the spatial encoding of targets when a visual discrimination needs to be performed, such as in the second stage of our task or when finding the target during visual search (Purcell et al., 2012), unlike the FEF with its more spatially dependent activity (Bruce and Goldberg, 1985; Schall and Hanes, 1993; Thompson et al., 1996). One possibility is that the SEF is involved in other cognitive or oculomotor processes during these discriminations; indeed, our SEF population encoded other task variables in the epochs during and surrounding the rule-implementing saccade. Neurons that were directionally selective during rule selection, in particular, showed a correlation between that selectivity and later rule selectivity during rule implementation. If this correlation reflects a causal, serial link, then this implies a mechanism in which directional selectivity in the first decision contributes to rule retrieval for the second decision. It is not obvious how that would work, but it emphasizes the potential complexity of neural processes that may link serial decisions.

\section{Rule selectivity}

We found that our SEF neural sample encoded task rules "justin-time," only when the rules were needed to make a decision, and not at the time that the rules were selected or instructed. Two other studies found significant rule-related in activity in SEF (White and Wise, 1999; Olson and Gettner, 2002). In one study, the authors did not report how SEF rule-related activity varied across the trial epochs (White and Wise, 1999). In the other, a 
single cue simultaneously instructed subjects both which rule to use ("attend to cue features" vs "attend to cue location") and where to look (the features or locations of that cue; Olson and Gettner, 2002). Our finding that the SEF encodes rules for visual discrimination at the time when a saccadic report is required is consistent with behavior of a patient with an SEF lesion who selectively showed task deficits in reporting decisions with eye movements but not reaches (Husain et al., 2003; Parton et al., 2007). More generally, this "just-in-time" representation of the rule suggests a specific role for the SEF in applying rules. Rather than maintaining the rule representation, the transient profile of the signal suggests that the SEF recalls a working memory of the rule only when context requires the rule to be used.

Neural activity in SEF was selective for rules, but not for how they were established; we found no modulation for the task condition of self-selected versus instructed. One possible explanation for this null result is that, because it is the rule that matters for the upcoming discrimination and not how the rule is established, task condition may be encoded in a brain region that is more likely to encode task-irrelevant variables such as PFC (Lauwereyns et al., 2001). Indeed, one human fMRI study reported differential encoding of rule selection versus rule instruction in the PFC (Zhang et al., 2013). Another possible explanation stems from the fact that, in our paradigm, even when rules are instructed, the subject still uses a saccade to "select" one of the rule targets. We designed the task this way to keep the patterns of stimuli and actions identical across all trials, but it may have prevented us from identifying activity specifically related to the selection of rules independent from the selection of saccade targets.

\section{Prospective and retrospective encoding of trial outcomes}

We found robust effects of trial outcome on SEF activity both before and after feedback delivery. Some SEF neurons encoded the outcome of the upcoming perceptual decision as early as 200 $\mathrm{ms}$ after the decision targets appeared. This prospective outcome encoding remained even after controlling for sensory features, objective discrimination difficulty, and other properties, suggesting that SEF neurons are signaling subjective likelihood of receiving reward. If SEF activity signals when errors will be made, then why does the animal not correct its chosen-but-not-yetimplemented decision? We would argue that this prospective SEF activity represents the expected trial outcome associated with the selected or instructed rule, marginalized over the upcoming perceptual choice. This is supported by the simultaneous presence of rule selectivity and prospective outcome encoding during the percstim epoch and the lack of selectivity for saccade direction during the rule implementation stage. SEF activity also has been shown to prospectively encode reward expectations when the reward probabilities are explicitly provided (So and Stuphorn, 2012) and confidence reports after the perceptual decisions on which they are based (Middlebrooks and Sommer, 2012). Therefore, the SEF may be important for the generalized prediction of future rewards regardless of whether the reward probabilities are explicitly provided or estimated internally.

We also found that SEF neuronal activity was modulated by the outcomes of past trials. Some neurons encoded the outcomes of the previous trial and the trial before that, but only proximal to the intertrial interval, when visual stimuli relevant for the current trial had yet to appear. Previous studies of SEF also found activity related to past trial outcomes (Middlebrooks and Sommer, 2012; Donahue et al., 2013) and one such study also found that past outcome encoding was present only during the intertrial interval
(Middlebrooks and Sommer, 2012). Both studies found that encoding of past trial outcomes occurred in other cortical regions as well, including the FEF, PFC, anterior cingulate cortex, and the lateral intraparietal area (Middlebrooks and Sommer, 2012; Donahue et al., 2013).

\section{Lack of sustained activity between decisions}

Our second hypothesis was that, like the sustained activity observed by Middlebrooks and Sommer (2012) that bridged a perceptual decision to a wager on whether it was correct, SEF activity in our task would link selection of a rule to its implementation for a perceptual decision. Instead, the activity encoded rules only at the time they were implemented. If the SEF does not maintain a trace of the rule once it is established, then where is it stored in working memory? A likely candidate region is the PFC, which showed no bridging activity between decisions in the Middlebrooks and Sommer (2012) study, but does encode rules robustly (Wallis et al., 2001; Buschman et al., 2012). A demonstration of sustained activity between rule selection and application in PFC using our task would provide an intriguing double dissociation between SEF and PFC, suggesting that they are used for linking serial decisions in different contexts: the SEF when perceptual decisions are monitored for later use and the PFC when rules are set for later perceptual decisions. One framework for describing this distinction is that SEF would be involved in metacognitive monitoring and PFC in metacognitive control of perceptual decisions (Nelson and Narens, 1990; Middlebrooks and Sommer, 2012). Another possible interpretation, which agrees with our finding of prospective outcome encoding, could be that the SEF generally encodes confidence in decisions (Middlebrooks and Sommer, 2012; So and Stuphorn, 2016). Because the rules are not ambiguous in our task, the lack of sustained task-related signals after a rule is established could reflect constant confidence in understanding it.

\section{Conclusion}

We found that SEF neurons encode key events in a serial decision-making task that required monkeys to select a rule and then use it for a visual decision. SEF activity encodes the spatial attributes of saccades depending on their function, encodes rules at the time when they can be integrated with visual evidence to report a decision, and encodes prospective and long-lasting trial outcome signals. As one of the foundations of continuous behavior, serial decision-making merits further study and it will be important to investigate the contributions of other candidate brain areas and how they work with the SEF to create the internal representations that link cognitive operations over time.

\section{References}

Abzug ZM, Sommer MA (2017) Supplementary eye fields. In: Reference module in neuroscience and biobehavioral psychology, pp 635-648. Amsterdam, the Netherlands: Elsevier.

Abzug ZM, Sommer MA (2018) Serial decision-making in monkeys during an oculomotor task. J Exp Psychol Anim Learn Cogn 44:95-102. CrossRef Medline

Amador N, Schlag-Rey M, Schlag J (2000) Reward-predicting and rewarddetecting neuronal activity in the primate supplementary eye field. J Neurophysiol 84:2166-2170. CrossRef Medline

Avdagic E, Jensen G, Altschul D, Terrace HS (2014) Rapid cognitive flexibility of rhesus macaques performing psychophysical task-switching. Anim Cogn 17:619-631. CrossRef Medline

Bruce CJ, Goldberg ME (1985) Primate frontal eye fields. I. Single neurons discharging before saccades. J Neurophysiol 53:603-635. CrossRef Medline

Buschman TJ, Denovellis EL, Diogo C, Bullock D, Miller EK (2012) Syn- 
chronous oscillatory neural ensembles for rules in the prefrontal cortex. Neuron 76:838-846. CrossRef Medline

Chafee MV, Goldman-Rakic PS (2000) Inactivation of parietal and prefrontal cortex reveals interdependence of neural activity during memoryguided saccades. J Neurophysiol 83:1550-1566. CrossRef Medline

Coe B, Tomihara K, Matsuzawa M, Hikosaka O (2002) Visual and anticipatory bias in three cortical eye fields of the monkey during an adaptive decision-making task. J Neurosci 22:5081-5090. CrossRef Medline

Dias EC, Segraves MA (1999) Muscimol-induced inactivation of monkey frontal eye field: effects on visually and memory-guided saccades. J Neurophysiol 81:2191-2214. CrossRef Medline

Donahue CH, Seo H, Lee D (2013) Cortical signals for rewarded actions and strategic exploration. Neuron 80:223-234. CrossRef Medline

Gold JI, Shadlen MN (2007) The neural basis of decision making. Annu Rev Neurosci 30:535-574. CrossRef Medline

Hays AV Jr, Richmond BJ, Optican LM (1984) A UNIX-based multiple process system for real-time data acquisition and control. WESCON Conference Proceedings 2:1-10.

Husain M, Parton A, Hodgson TL, Mort D, Rees G (2003) Self-control during response conflict by human supplementary eye field. Nat Neurosci 6:117-118. CrossRef Medline

Judge SJ, Richmond BJ, Chu FC (1980) Implantation of magnetic search coils for measurement of eye position: an improved method. Vision Res 20:535-538. CrossRef Medline

Kawaguchi N, Sakamoto K, Saito N, Furusawa Y, Tanji J, Aoki M, Mushiake H (2015) Surprise signals in the supplementary eye field: rectified prediction errors drive exploration-exploitation transitions. J Neurophysiol 113:1001-1014. CrossRef Medline

Kim YG, Badler JB, Heinen SJ (2005) Trajectory interpretation by supplementary eye field neurons during ocular baseball. J Neurophysiol 94: 1385-1391. CrossRef Medline

Lauwereyns J, Sakagami M, Tsutsui K, Kobayashi S, Koizumi M, Hikosaka O (2001) Responses to task-irrelevant visual features by primate prefrontal neurons. J Neurophysiol 86:2001-2010. CrossRef Medline

Lee D, Seo H (2016) Neural basis of strategic decision making. Trends Neurosci 39:40-48. CrossRef Medline

MacPherson JM, Aldridge JW (1979) A quantitative method of computer analysis of spike train data collected from behaving animals. Brain Res 175:183-187. CrossRef Medline

Mann SE, Thau R, Schiller PH (1988) Conditional task-related responses in monkey dorsomedial frontal cortex. Exp Brain Res 69:460-468. Medline

Middlebrooks PG, Sommer MA (2011) Metacognition in monkeys during an oculomotor task. J Exp Psychol Learn Mem Cogn 37:325-337. CrossRef Medline

Middlebrooks PG, Sommer MA (2012) Neuronal correlates of metacognition in primate frontal cortex. Neuron 75:517-530. CrossRef Medline

Missal M, Heinen SJ (2004) Supplementary eye fields stimulation facilitates anticipatory pursuit. J Neurophysiol 92:1257-1262. CrossRef Medline

Nelson TO, Narens L (1990) Metamemory: A theoretical framework and new findings. In: The psychology of learning and motivation, Vol 26 (Bower GH, ed), pp 125-173. Waltham, MA: Academic.

Nyffeler T, Rivaud-Pechoux S, Wattiez N, Gaymard B (2008) Involvement of the supplementary eye field in oculomotor predictive behavior. J Cogn Neurosci 20:1583-1594. CrossRef Medline

Olson CR, Gettner SN (1995) Object-centered direction selectivity in the macaque supplementary eye field. Science 269:985-988. CrossRef Medline

Olson CR, Gettner SN (1999) Macaque SEF neurons encode objectcentered directions of eye movements regardless of the visual attributes of instructional cues. J Neurophysiol 81:2340-2346. CrossRef Medline

Olson CR, Gettner SN (2002) Neuronal activity related to rule and conflict in macaque supplementary eye field. Physiol Behav 77:663-670. CrossRef Medline

Parton A, Nachev P, Hodgson TL, Mort D, Thomas D, Ordidge R, Morgan PS, Jackson S, Rees G, Husain M (2007) Role of the human supplementary eye field in the control of saccadic eye movements. Neuropsychologia 45:997-1008. CrossRef Medline

Purcell BA, Weigand PK, Schall JD (2012) Supplementary eye field during visual search: salience, cognitive control, and performance monitoring. J Neurosci 32:10273-10285. CrossRef Medline

Russo GS, Bruce CJ (1996) Neurons in the supplementary eye field of rhesus monkeys code visual targets and saccadic eye movements in an oculocentric coordinate system. J Neurophysiol 76:825-848. CrossRef Medline

Schall JD, Hanes DP (1993) Neural basis of saccade target selection in frontal eye field during visual search. Nature 366:467-469. CrossRef Medline

Schiller PH, Chou IH (1998) The effects of frontal eye field and dorsomedial frontal cortex lesions on visually guided eye movements. Nat Neurosci 1:248-253. CrossRef Medline

Schlag J, Schlag-Rey M (1987) Evidence for a supplementary eye field. J Neurophysiol 57:179-200. CrossRef Medline

Schlag-Rey M, Amador N, Sanchez H, Schlag J (1997) Antisaccade performance predicted by neuronal activity in the supplementary eye field. Nature 390:398-401. CrossRef Medline

Shadlen MN, Kiani R (2013) Decision making as a window on cognition. Neuron 80:791-806. CrossRef Medline

So N, Stuphorn V (2012) Supplementary eye field encodes reward prediction error. J Neurosci 32:2950-2963. CrossRef Medline

So N, Stuphorn V (2016) Supplementary eye field encodes confidence in decisions under risk. Cereb Cortex 26:764-782. CrossRef Medline

Sommer MA, Tehovnik EJ (1997) Reversible inactivation of macaque frontal eye field. Exp Brain Res 116:229-249. CrossRef Medline

Sommer MA, Tehovnik EJ (1999) Reversible inactivation of macaque dorsomedial frontal cortex: effects on saccades and fixations. Exp Brain Res 124:429-446. CrossRef Medline

Sommer MA, Wurtz RH (2004) What the brain stem tells the frontal cortex. I. oculomotor signals sent from superior colliculus to frontal eye field via mediodorsal thalamus. J Neurophysiol 91:1381-1402. CrossRef Medline

Stoet G, Snyder LH (2003) Executive control and task-switching in monkeys. Neuropsychologia 41:1357-1364. CrossRef Medline

Stokes MG, Kusunoki M, Sigala N, Nili H, Gaffan D, Duncan J (2013) Dynamic coding for cognitive control in prefrontal cortex. Neuron 78:364375. CrossRef Medline

Stuphorn V, Taylor TL, Schall JD (2000) Performance monitoring by the supplementary eye field. Nature 408:857-860. CrossRef Medline

Thompson KG, Hanes DP, Bichot NP, Schall JD (1996) Perceptual and motor processing stages identified in the activity of macaque frontal eye field neurons during visual search. J Neurophysiol 76:4040-4055. CrossRef Medline

Uchida Y, Lu X, Ohmae S, Takahashi T, Kitazawa S (2007) Neuronal activity related to reward size and rewarded target position in primate supplementary eye field. J Neurosci 27:13750-13755. CrossRef Medline

Wallis JD, Anderson KC, Miller EK (2001) Single neurons in prefrontal cortex encode abstract rules. Nature 411:953-956. CrossRef Medline

Washburn DA (1994) Stroop-like effects for monkeys and humans: processing speed or strength of association? Psychol Sci 5:375-379. CrossRef Medline

White IM, Wise SP (1999) Rule-dependent neuronal activity in the prefrontal cortex. Exp Brain Res 126:315-335. CrossRef Medline

Zhang J, Kriegeskorte N, Carlin JD, Rowe JB (2013) Choosing the rules: distinct and overlapping frontoparietal representations of task rules for perceptual decisions. J Neurosci 33:11852-11862. CrossRef Medline 